\title{
Anxiety with and Without New Technology Among Romanian High School Students
}

\section{Elena Cocoradă}

Cătălin Ioan Maican

Transilvania University of Braşov, Romania

\begin{abstract}
Nowadays, the new technology defines the classroom and students' and teachers' life. Sometimes the attitude towards technology use is marked by negative dysfunctional emotion, anxiety, fear, avoidance or dependence. This paper focuses both on the anxiety with the new technology and on the anxiety without technology. Our research aims to examine the attitudes and behaviours of Romanian high school students regarding trendy technologies, such as computers, internet and smartphones, including the access to social networking applications. The following tools were used: CARS (Heinssen, Glass, \& Knight, 1987), IAS (Nickel and Pinto, 1986), four scales from MTUAS (Rosen, Whaling, Carrier, Cheever, and Rokkum, 2013), the Use of Smartphones for Learning Purposes Scale-USLS and a socio-demographic questionnaire. There were 517 participants distributed in two studies. The findings showed some differences concerning gender, age, specialization and academic performance, as well as an evolution of participants from the anxiety towards the computer (highest with females) to the anxiety without technology (similar for females and males). School performance is negatively associated with computer anxiety and Facebook activities. The study is important in the Romanian context, where computers, internet and smartphone penetration is more pronounced with younger people. Pedagogical issues of the research are also discussed, anxiety having a double function, as an endogenous and exogenous factor with respect to one's academic and professional development.
\end{abstract}

Keywords: anxiety, computer, internet, smartphone, high school students.

\section{Introduction}

\section{Forms of academic anxiety}

Nowadays, the new technology defines the classroom and the lives of students and teachers. The acceptance of the new technology concept in the learning area focuses especially on communication technology, like computers, tablets, internet and smartphones. The attitudes concerning these devices are variable, depending on gender, age, cultural context or the decade research (King et al., 2014; Powell, 2013).

As a consequence of technical and social developments, the research studies first put emphasis on the anxiety towards computers and the internet. This is a specific anxiety, associated with a specific situation, revealed in negative emotional reactions towards using computers, negative expectations concerning equipment damage, fatal consequences of the errors in use, or stress and frustration (Oetting, 1983; Phelps \& Ellis, 2009). The anxiety towards computers and the internet is similar to math anxiety, or to the anxiety towards foreign languages and all the specific anxieties developed during school, which are cumulated under the umbrella-concept of academic anxiety (Cassady, 2010; Cazan, Cocorada, Maican, 2016). This specific anxiety is positively associated with the general trait of anxiety (Thatcher \& Perrewé, 2002).

Over the recent years, research studies have emphasised the anxiety without technology. Called nomophobia or dependence on technology, it focuses on new behavioural addictions, including smartphone addiction (Dixit et al., 2010; Sapacz, Rockman, \& Clark, 2016). The anxiety without technology is a situational anxiety, experienced as fear of not being able to use a smartphone or the internet, being beyond mobile phone contact, not being able to access information, or losing the connectedness and the services it offers (King et al., 2014). Both forms, the anxiety towards the computer or the internet, and the anxiety without technology, are the extremes of the continuum. 


\subsection{Research context}

The penetration and widespread use of ICTs in Romania have marked the second decade of this century: in 2013, more than half of all households had a computer $(55.8 \%)$, most were located in urban areas $(69.8 \%)$, and over half of the households had access to the internet (52.9\%) (INS, 2013a). 60.3\% of all persons aged between 16 and 74 years have used a computer at least once, men (61.8\%) more frequently than women (58.8\%). Among those aged between 6 and 34 years, $90 \%$ have used a computer. The mobile phone and smartphone penetration is more pronounced with younger people, aged between 16 and 34 (74.4\%), more highly educated people (62.3\%) and males (49.7\%). For accessing the internet, the smartphone is the most widely used nowadays $(61.8 \%)$, followed by the portable computer (47.5\%) (INS, 2013b).

In the described context, the analysis of the anxiety and the associated behaviours of high school students, owners of computers and smartphones, is critical. Since most of the high schools in Romania can be found in urban areas, our research was conducted in this environment.

\section{Short literature review}

\subsection{The anxiety towards the computer and the internet}

Early studies in the field reported that the anxiety towards the computers and the internet is higher in the case of females, older people and persons with lower competences (Igbaria, \& Chakrabarti, 1990; Powell, 2013). Based on gender role differences, some authors found that males report more frequent use of computers and tend to have a more positive attitude towards this device than females (e.g. Chou, J., \& Tsai, H., 2009; Nickell, 1987). Researchers have found that younger people report lower levels of anxiety towards the computer and the internet (e.g. Kubiatko et al., 2011).

Previous studies also show that people with low performance in mathematics have high anxiety and poor performance in computing (Glass \& Knigth, 1988). Other studies found that a high computer self-efficacy decreases the anxiety towards computers and reduces technostress Error! Reference source not found.; Shu et al, 2011). According to other studies, females have lower average computer self-efficacy than males Error! Reference source not found.), but not all findings are convergent. Concerning the relations between school performance and computer anxiety, some studies found a negative relationship, while others showed that anxiety moderates the relationship between academic self-efficacy and learning performance (Powell, 2013; Shakir, 2014).

\subsection{Anxiety without technology and task switching}

The studies focused on the anxiety without technology found that females are significantly less dependent than males, while older people show a less positive attitude towards technology and report a lower level of the anxiety without technology than younger people. More highly educated people report a higher level of anxiety without technology compared to less educated persons. The Facebook usage was most significantly correlated with the anxiety about not checking in often enough with the social network. Similar results were seen for each application of the smartphone, like emailing, phone calling, messaging, internet searching (Rosen et al., 2013).

Task switching, or media multitasking, is the consumption of two or more streams of content, facilitated by technology, and has several undesired outcomes (Terry et al, 2016). A study from 2013 found that media multitasking is not correlated with age, but the participants who preferred more to task-switch showed more dependency on technology and less positive attitudes (Rosen et al., 2013). Other research studies state that, in an experimental context, the younger individuals switch more often than the older ones (e.g. Brasel \& Gips, 2011). The students who prefer multitasking are especially freshmen (Junco, 2015) and tend to have negative academic performance (Wood \& Zivcakova, 2015). Numerous studies have showed that media multitasking was associated with higher depression and social anxiety, even after controlling for overall media use and for the personality traits of neuroticism and extraversion (Becker, Alzahabi,\& Hopwood, 2013).

\subsection{The consequences of anxiety in the academic field}

The consequences of anxiety towards technology on academic performance and on the students' personal development are ambivalent, positive and negative simultaneously, depending on the personality traits, goals, duration and frequency of use. The paradoxical duality of the new media usage (Hoffman \& Novak, 1996) showed that, in the short-term, the usage implies more benefits than drawbacks, while in the long-term, this usage is followed by addictive and impulsive behaviours. 
Our research aims to analyse the anxiety with and without technology among Romanian high school students. We have designed two studies, the first one in 2012-2013 (Study 1) and the second one after 3 years (Study 2), in line with the dynamics of the social context. The objectives, hypotheses, tools and results will be presented separately for the two studies, being followed by the unique discussion section, to achieve dynamic comparisons and highlight the consequences. The research was a descriptive and correlational one.

\section{Study 1}

\subsection{Objectives and hypothesis}

The objective of the first research was to analyse the differences generated by gender, age and specialization as regards the computer and internet use. We supposed that (1) the anxiety towards the computer and the internet is higher for women, older students and those in the Humanities; (2) computer and internet anxiety is associated with school performance.

\subsection{Participants and tools}

The participants were 234 female and male students in secondary education, out of which $44.2 \%$ are boys, $51.3 \%$ being enrolled in Sciences. 99.3\% own a computer and have access to the internet. The tools used were two self-report inventories: Computer Anxiety Rating Scale-CARS (1987) and the Internet Attitude Scale-IAS (1986). Higher scores indicate high degrees of computer and internet anxieties.

CARS, elaborated by Heinssen, Glass, \& Knight, is a 19-item instrument, used with a four-point Likert scale (1=strongly disagree, $2=$ disagree, $3=a g r e e$, and $4=$ strongly agree). Higher scores indicate a high degree of computer anxiety. We have used the version of Harrison and Rainer (1992) with two factors: Fear (10 items and alpha Cronbach=0.85) and Anticipation (9 items and alpha Cronbach=0.84). Items examples: I feel insecure about my ability to interpret a computer printout. I hesitate to use a computer for fear of making mistakes that I cannot correct. I feel computers are necessary tools in both educational and work settings.

IAS is a tool adapted in order to assess the attitude towards the internet according to a scale built by Nickel and Pinto. IAS consists of 20/18 items and the Likert scale is a five-point one (alpha Cronbach $=0.80$ for 18 items). Example items: Computers make me uncomfortable because I don't understand them, Life will be easier and faster with computers, I feel intimidated by computers.

\subsection{Results}

On the entire sample, the level of anxiety towards the computer has an average of $47.7(S D=3.88)$, $\min .=38$ and $\max .=$ 69. The average level of the anxiety towards the internet has the value of $48.62(S D=4.88) \min .=37$ and max. $=59$. The analysis by gender, age and specialization indicates some significant differences (Table 1). In the entire sample, GPA is negatively correlated only with the mean score regarding the fear of computer $(r=-0.170, p<0.05)$.

Table 1 Gender, age and specialization field differences concerning the anxiety towards the computer and the internet

\begin{tabular}{|c|c|c|c|c|c|c|c|c|}
\hline & \multicolumn{4}{|c|}{ Anxiety towards the computer } & \multicolumn{4}{|c|}{ Anxiety towards the internet } \\
\hline & Mean & SD & $t$ & Cohen's d & M & SD & $t$ & Cohen's d \\
\hline \multicolumn{9}{|l|}{ Gender } \\
\hline$F$ & 48.89 & 2.90 & \multirow{2}{*}{$3.38^{* *}$} & \multirow{2}{*}{0.57} & 48.85 & 4.82 & \multirow{2}{*}{.474} & \multirow{2}{*}{0.08} \\
\hline$M$ & 46.80 & 4.25 & & & 48.47 & 4.95 & & \\
\hline \multicolumn{9}{|l|}{ Age } \\
\hline Until 16 years & 47.73 & 4.47 & \multirow[t]{3}{*}{.28} & \multirow{3}{*}{0.02} & 49.52 & 4.96 & \multirow{3}{*}{$2.34^{\star *}$} & \multirow{3}{*}{0.38} \\
\hline After 16 years & 47.67 & 3.23 & & & 47.68 & 4.66 & & \\
\hline Specialization & & & & & & & & \\
\hline Humanities & 48.62 & 3.84 & \multirow[t]{2}{*}{$2.69^{* \star}$} & \multirow{2}{*}{0.43} & 48.47 & 4.68 & \multirow{2}{*}{.381} & \multirow{2}{*}{0.06} \\
\hline Sciences & 46.92 & 3.75 & & & 48.77 & 5.13 & & \\
\hline
\end{tabular}

Note: ${ }^{*} p<.05,{ }^{* *} p<.01, M-$ mean, $S D$ - standard deviation 


\section{Study 2}

\subsection{Objectives and hypothesis}

Our objective was to analyse the relationships between the use of the smartphone and the anxiety without technology in the case of high school students. We supposed that: (1) the anxiety without technology is higher in the case of male students (2) the smartphone applications are used extensively by boys and the students in Sciences, (3) the attitudes of the participants are ambivalent, positive and negative, (4) there is an association between the school performance and the attitudes towards technology, (5) there are differences in point of the school performance, given by the possession of the Facebook account.

\subsection{Participants}

This study involved 283 students, girls (57.3\%) and boys (42.7\%), the Humanities comprising $41.6 \%$ of the total sample. $35.6 \%$ of the students are less than 16 years old. If in 2013 only $6.6 \%$ students owned a smartphone, in 2016, the proportion has massively increased $(95.2 \%)$ on the sample we investigated. The self-reported duration for using the smartphone is 4.5 hours per day, on the average. The smartphone is used $2-3$ hours a day by $33.7 \%$ of the participants, $4-6$ hours by $49.2 \%$ and $10 \%$ use it more than 7 hours per day.

\subsection{Tools}

The tools used are the Use of Smartphones for Learning Purposes Scale-USLS, elaborated by Rung, Wranke, and Mattheos (2014) and the Media and Technology Usage and Attitudes Scale (MTUAS), elaborated by Rosen, Whaling, Carrier, Cheever, and Rokkum (2013).

The USLS is structured into three parts, but we have used only Part B, comprising questions which explore in particular the use of the smartphone for learning purposes, including the use of social media. MTUAS is a tool with more subscales, but we have used only the third part in this research. The factorial analysis of this section has showed four factors which we labelled 1-Anxiety without technology, 2-Negative attitude, 3-Positive attitude, and 4-Task switching. For each factor, we have detained items with saturation greater than .55. Example items: I feel it is important to be able to find any information whenever I want online. When doing a number of assignments, I like to switch back and forth between them rather than do one at a time. I get anxious when I don't have my cell phone. Three items grouped in the scale called Anxiety without technology reflect the anxiety related to being without a phone or the internet and, as a consequence, the technological dependence (Rosen et al., 2013). The task switching scale includes the items that express the tendency to shift attention from one task to another.

\subsection{Results}

The anxiety without technology is reported in the investigated sample $(M=7.86, S D=2.9)$, but the differences between genders were not identified. The reported attitudes of teenagers are simultaneously positive and negative, the negative being more pronounced among girls $(F)(t=2.28, p<0.05)$. Boys $(M)$ tend to task switch more $(t=1.78, p=0.07$, a marginal significance) (Table 2).

Table 2 Gender differences concerning the attitudes towards technologies and task switching

\begin{tabular}{|c|c|c|c|c|c|}
\hline & Gender & Mean & Std. Deviation & Test $\mathrm{t}$ & Cohen's d \\
\hline \multirow[b]{2}{*}{ Anxiety without technology } & $\mathrm{F}$ & 8.13 & 2.84 & \multirow[b]{2}{*}{1.45} & \multirow[t]{2}{*}{0.18} \\
\hline & M & 7.60 & 2.98 & & \\
\hline \multirow{2}{*}{ Positive attitude towards technology } & $\mathrm{F}$ & 14.00 & 2.91 & 120 & \multirow[t]{2}{*}{0.14} \\
\hline & M & 14.43 & 3.11 & & \\
\hline \multirow{2}{*}{ Negative attitude towards technology } & $\mathrm{F}$ & 10.96 & 2.99 & $228^{*}$ & \multirow[t]{2}{*}{0.28} \\
\hline & & 10.14 & 2.89 & & \\
\hline \multirow{2}{*}{ Task switching } & $\mathrm{F}$ & 9.33 & 2.98 & \multirow{2}{*}{1.78} & \multirow[t]{2}{*}{0.22} \\
\hline & M & 9.98 & 3.04 & & \\
\hline
\end{tabular}


Students aged under 16 use the smartphone to a significantly greater extent than their peers $(t=2.58, p<0.01)$. Science students compared to Humanities students report more positive attitudes $(t=3.25, p<0.01)$ and a more competent usage of smartphone applications $(t=2.28, p<0.05)$.

The anxiety without technology directly correlates with the favourable attitudes towards technology $(r=0.40, p<0.01)$, task switching $(r=0.16, p<0.01)$, smartphone usage $(r=0.25, p<0.01)$, and Facebook usage $(r=0.25, p<0.05)$. The students who use more the smartphone have had a computer $(r=-0.21, p<0.01)$ and internet access $(r=-0.19, p<0.01)$ for a shorter period of time and have emphasized positive attitudes towards the technology $(r=0.246, p<0.01)$. Similarly, the students who use Facebook more say they have had a computer $(r=-0.13, p<0.01)$ and internet access $(r=-0.13, p$ $<0.05)$ for a short period of time. Their school results do not correlate with any of the variables above, excluding task switching, indirectly associated with GPA $(r=-0.12, p<0.05)$.

In our sample, $97.9 \%$ of the students check their Facebook page using the smartphone. Female students, more than male ones, check their Facebook page at school $(t=2.25, p<0.05)$. The students' Facebook activities are:

- Profile reading - 31.6\% "multiple times per day" and 38.9\% "all the time",

- Liking posts, photos etc. - 30.8\% "many times per day" and $44.6 \%$ - "all the time",

- Post comments - 21.5\% "several times per day" and 22.6\% "all the time",

- Searching for profiles and photos - 19.4\% "multiple times per week" and 15.2\%- "all time

- Photo posting - $18.7 \%$ "multiple times per week",

- Updating their status - with the modal value $17.7 \%$ for the option "multiple times per week".

The use of all listed Facebook activities are negative and strongly associated with the students' grades, the correlation coefficients being between -0.13 and $-0.21(0.01<p<0.05)$. Although some students say they use Facebook to learn, there are differences in point of the GPAs, given by the possession of a Facebook account $(t=2.16, p<0.05)$.

\section{Discussion and conclusions}

The adoption of the computer and of the communication devices, with a fast rate in the last decade of this century, has activated some states and behaviours similar to those already identified in other, more developed countries. The selfreported anxiety towards the computer and the internet and the anxiety without technology are present in the case of the high-school students who participated in our research. These students own computers (over 99\%) and smartphones (over $95 \%$ ) to a very large extent. Younger high-school students (aged below 16) do not have lower anxiety levels towards the computer compared to their older mates, while they use the smartphone significantly more. These younger high-school students declare themselves more anxious regarding using the internet compared to the latter. We appreciate that the internet anxiety could be mimed or induced to these students by their parents or teachers, being probably a public conformism. But they do not report higher levels for the anxiety without technology.

Our findings support the hypothesis of gender and specialization differences concerning the anxiety towards the computer and the internet. The anxiety towards the computer is more pronounced in the case of girls and Humanities students, confirming other studies, and it is probably explained by their lower competences compared to boys and Sciences students, or by internalizing gender stereotypes.

In line with other studies (Rosen et al., 2013), smartphone usage, as well as task switching, is higher for students who report a higher anxiety without technology. In contrast to other studies, in our sample girls and boys reported equal levels of anxiety without technology. Probably the equal level is a consequence of the easier usage of the smartphone and can be interpreted as a levelling trend of the attitudes towards the new technologies specific to this decade. This tendency marks the beginning of the diminishing of gender differences concerning computers, also explained by the increasingly wider access to learning for both genders (Durndell et al, 2002; Cazan, Cocorada, \& Maican, 2016), but the levelling of anxiety without technology is socially undesirable.

The positive attitudes towards the new technology are more pronounced in the case of Sciences students compared to the Humanities ones, just like their capacity to use more varied smartphone applications, confirming other studies (Rosen et 
al. 2013; Terry et al, 2016). Negative attitudes are stronger with girls, who probably have less knowledge and self confidence in this domain.

Students experiencing uncomfortable feelings in the absence of devices or of the access to online communication have more favourable attitudes toward IT technologies, as in Rosen et al. (2013), and they switch between tasks more often, use smartphones and Facebook more. In our study, the preference for task switching was strongly correlated with the smartphone use, in contrast with other studies (e.g. Terry et al., 2016). Contrary to cited research (e.g. Rosen et al., 2013), our study did not show a higher tendency to task switching for the participants with less positive attitudes.

For the subject Informatics, we identified a significant association between academic performance and anxiety only for the "fear of computer" component of the computer anxiety construct. The students for whom the fear of computer use is more intense, have lower performance in this subject, confirming that anxiety is reduced by the competences in this field. GPA is not associated with the anxiety without technology, unlike task switching, whose increase is correlated with the simultaneous decrease in school performance, according to studies from other countries. Similarly, the students who are more active on Facebook reported lesser school performance. The GPAs are lower for the students who own a Facebook account (Terry et al., 2016; Wood et al., 2015). In this case, we propose two explanations: the students with lesser performance prefer the activities on Facebook as compensation, or the frequent access of Facebook wastes their learning time.

Regarding the limits of this study, first we underline the unrandomized sample, and secondly, the disadvantage of not being an effective longitudinal study. For future research, we propose to use a representative sample in a longitudinal survey and to include additional variables, such as self-efficacy, resilience and well-being. Using other methods such as qualitative ones, we can explain the different participants' options and motivations. Expanding the research at lower secondary level (11-14 years old) is an opportunity.

\section{Implications for the school environment}

The smartphones, the computers and the internet present a significant potential as learning tools, and cause changing habits in the classroom. These technologies were not included everywhere in the formal curriculum, but some authors underline the opportunity to design adequate educational methods, activities and material (Oulasvirta et al., 2012; Rung et al., 2014).

The computer and the internet could be sources for advantages in learning and in one's personal development, facilitating the fast access to information anytime and anywhere, or providing compensation for the difficulty of interpersonal relations in real live. The optimistic assumptions look at the use of the computer and the internet as a premise for a cognitive challenging task: it can facilitate information processing, the exchange of information, maximizing resources. For these and other reasons, the anxiety towards the computer and the internet can alter communication, social relationships or can impinge on the acquisition of useful skills in learning and in one's further professional activity (Heinssen, Glass, \& Knight, 1987). The consequences are important because anxiety has a double function, as an endogenous and exogenous factor, in connection with one's academic, professional and personal development.

The listed findings can be an argument for differentiating learning and students' counselling. The difficulty to design teaching scenarios for students with different attitudes and abilities can be a pedagogical challenge (Sung, \& Chan 2016) and, in our opinion, this difficulty is significant for the teachers who feel themselves anxious about technology. The presence of this category, including the schools in Romania (Cocoradă, 2014), implies, as a priority, an adequate teachers' training.

The negative consequences of new communication technologies are present in the students' life: long term usage of the internet or smartphone as coping strategies may have a negative influence on mental health and on relationships. Although the use of phones, computers and the internet can sometimes reduce boredom, excessively using this behaviour for emotional coping may increase depression and can be associated with health compromising behaviours, such as smoking or alcohol (Panova \& Lleras, 2016; Sanders, Field, Diego, \& Kaplan, 2002). The problematic use of these devices increases the procrastinating regarding homework, missing classes and dropout (Leena, Tomi, \& Arja, 2005; Panova \& Lleras, 2016; Sanders et al., 2000).

On the other hand, task switching reduces attention focusing during the lesson, and decreases the quality of learning outcomes. The exacerbated use of new technologies disturb behaviour and feelings, leading to social isolation (Bragazzi 
\& Del Puente, 2014) and can introduce visible negative changes in the individuals' daily behaviour (King et al, 2013). Facebook and the smartphone use have a positive effect on leisure activities (Janković, Nikolić, Vukonjanski, \& Terek, 2016), but a negative one on school performance. In this context, in order to help their students reduce the perceived anxiety and techostress, teachers must manage their students' computer self-efficacy.

Multifaceted interventions, including self-efficacy, made by school counsellors can be a solution. In a similar study, we found that the anxiety towards the computer and the internet is negatively associated with self-efficacy, including assisted self-efficacy and independent self-efficacy, obtained by us after the factorial analyses of the instrument of Compeau and Higgins (1995) (Cocoradă \& Pălăşan, 2014). In our opinion and according to specific items, assisted self-efficacy is a positive feeling about one's own computer skills, updated in the presence of the help given by others, and it is higher with girls and Humanities students. We suppose that this type of self-efficacy can be used in counselling intervention for the reduction of female computer anxiety.

Although the students in our study report that they use smartphones for learning, their school performance is lower than that of their less dependent colleagues. It is possible that the usage of smartphones for social and private activities be dominant compared to its use for learning, as other studies show (Sanders, 2012). Smartphone usage can ease access to the internet, but using it in the classroom or at home concurrently with school activities or homework, avoiding outdoor activities or direct interpersonal relationships, is harmful. The students' misunderstanding of the negative consequences of using new technologies produces disadvantages: performance diminishing, sleep disorders, relational disorders. In these cases, primary prevention must avoid the subsequent appeal to medication or psychotherapy, more costly than secondary intervention.

The paradoxical duality of the new technologies, reconfirmed in our sample by the students' ambivalent attitudes, requires in school an approach which should avoid extremes. The emotional ambivalence towards technology could be relevant for a relatively critical attitude towards using the smartphone and, implicitly, it could be used as a premise for developing critical thinking and rational behaviour. In the presence of the divergent effects of new technologies, the appropriate behaviour of adults, parents and teachers must be differentiated: organizing a learning environment that reduces anxiety, but keeping them open to avoid abuse or dependence.

The assimilation of the complex attitudes towards the new technologies and the development of the control capacity are even more difficult when the students' age is lower. But it is even more important in the educational space because of its stronger negative effects at younger ages, when the dependence on technology is higher.

\section{[1] References}

[1] Becker, M. W., Alzahabi, R., \& Hopwood, C. J. (2013). Media Multitasking Is Associated with Symptoms of Depression and Social Anxiety". Cyberpsychology, Behavior, and Social Networking, 16(2), 132-135.

[2] Bragazzi, N.L. \& Del Puente, G. (2014). A proposal for including nomophobia in the new DSM-V. Psychology Research and Behavior Management, 7, 155-160.

[3] Brasel, S. A., \& Gips, J. (2011). Media multitasking behavior: Concurrent television and computer usage. Cyberpsychology, Behavior and Social Networking, 14(9), 527-534.

[4] Cassady, J. C. (2010). Test anxiety: Contemporary theories and implications for learning. In J. C. Cassady (Ed.), Anxiety in schools: The causes, consequences, and solutions for academic anxieties, p. 7-26, New York, NY: Peter Lang.

[5] Cazan, A. M., Cocoradă, E., \& Maican, C. I. (2016). Computer anxiety and attitudes towards the computer and the internet with Romanian high-school and university students. Computers in Human Behavior, 55, 258-267.

[6] Chou, J., \& Tsai, H. (2009). On-line learning performance and computer anxiety measure for unemployed adult novices using a grey relation entropy method. Information Processing and Management, 45(2), 200-215.

[7] Cocoradă, E. (2014). Computer anxiety and motivation for learning of future teachers, The International Scientific Conference Elearning and Software for Education, 3, 90-95. Bucharest: „Carol I" National Defence University.

[8] Cocoradă, E., \& Pălăşan, T. (2014). Computer Anxiety and self-efficacy for highschool students: The International Scientific Conference Elearning and Software for Education, 3, 90-95. Bucharest: „Carol I" National Defence University.

[9] Compeau, D. R., \& Higgins, C.A. (1995). Computer Self-Efficacy: Development of a Measure and Initial Test. Management Information Systems Quarterly, 19(2), 189-211. 
[10] Dixit, S., Shukla,H., Bhagwat, A. K, Bindal, A., Goyal, A., Zaidi, A. K, \& Shrivastava, A. (2010). A Study to Evaluate Mobile Phone Dependence among Students of a Medical College and Associated Hospital of Central India. Indian Journal of Community Med, 35(2), 339-341.

[11] Durndell, A., Haag, Z., \& Laithwaite, H. (2000). Computer self-efficacy and gender: A cross cultural study of Scotland and Romania. Personality and Individual Differences, 28, 1037-1044.

[12] Harrison, A. W., \& Rainer, R. K. (1992). An Examination of the Factor Structures and Concurrent Validities for the Computer Attitude Scale, the Computer Anxiety Rating Scale, and the Computer Self-Efficacy Scale. Educational and Psychological Measurement, 52(3), 735-745. http://doi.org/10.1177/0013164492052003024

[13] Heinssen, R. K., Glass, C. R., \& Knight, L. A. (1987). Assessing computer anxiety: Development and validation of the computer anxiety rating scale. Computers in Human Behavior, 3, 49-59.

[14] Hoffman, D. L. \& Novak, T. P. (1996). Marketing in hypermedia computer-mediated environments: conceptual foundations. Journal of Marketing, 60, 50-68.

[15] Igbaria, M., \& Chakrabarti, A., (1990). Computer anxiety and attitudes towards microcomputer use. Behaviour \& Information Technology, 9(3), 229-241.

[16] Institutul National de Statistică [National Institute of Statistics](2013a). Utilizarea timpului in România [The use of time in Romania] http://www. insse.ro/cms/files/statistici/comunicate/com_anuale/util_

[17] timpul/utilizarea_timpului_r13.pdf

[18] Institutul National de Statistică. [National Institute of Statistics] (2013b). Accesul populaţiei la tehnologia informaţiilor şi comunicaţiilor în anul 2013. [People's access to technology of information and communication in 2013]. Retrieved from http://www.insse.ro/cms/files/statistici/comunicate/ com_anuale/tic/tic_r2013.pdf

[19] Janković, B., Nikolić, M., Vukonjanski, J., \& Terek, E. (2016). The impact of Facebook and smart phone usage on the leisure activities and college adjustment of students in Serbia. Computers in Human Behavior, 55, 354363. http://doi.org/10.1016/j.chb.2015.09.022

[20] Junco, R. (2015). Student class standing, Facebook use, and academic performance. Journal of Applied Developmental Psychology, 39, 18-29.

[21] King, A. S., Valença, A. M., Silva, A. O., Baczynski, T., Carvalho, M. R., \& Nardi, A. E. (2013). Nomophobia: dependency on virtual environments or social phobia? Computers in Human Behavior, 29(1), 140-144.

[22] KUBIATKO, M., HALÁKOVÁ, Z., NAGYOVÁ, S., \& NAGY, T. (2011). SLOVAK HIGH SCHOOL STUDENTS' ATTITUDES TOWARD COMPUTERS, INTERACTIVE LEARNING ENVIRONMENTS, 19(5), 537-550.

[23] Leena, K., Tomi, L., \& Arja, R. R. (2005). Intensity of mobile phone use and health compromising behaviours how is information and communication technology connected to health-related lifestyle in adolescence. Journal of Adolescense, 28(1), 35-47.

[24] Nickell, G. S., \& Pinto, J. N. (1986). The computer attitude scale, Computers in Human Behavior, 2, 301-306.

[25] Oetting, E. R. (1983). Oetting's computer anxiety scale (COMPAS). Ft. Collins, CO: Rocky Mountain Behavioral Science Institute.

[26] Oulasvirta, A., Rattenbury, T., Ma, L., \& Raita, E. (2012). Habits make smartphone use more pervasive. Personal and Ubiquitous Computing, 16(1), 105-114.

[27] Panova, T., Lleras, A. (2016). Avoidance or boredom: Negative mental health outcomes associated with use of Information and Communication Technologies depend on users' motivations. Computers in Human Behavior, 58, 249-258.

[28] Phelps, R. \& Ellis, A., 2009. Overcoming computer anxiety through reflection on attribution. Paper in http://www.ascilite.org.au/conferences/auckland02/proceedings/paper/076.pdf

[29] Powell, A. L. (2013). Computer anxiety: Comparison of research from the 1990s and 2000s, Computers in Human Behavior, 29, 2337-2381.

[30] Rosen, L. D., Whaling, K., Carrier, L. M., Cheever, N. A., \& Rokkum, J. (2013). The Media and Technology Usage and Attitudes Scale: An empirical investigation. Computers in Human Behavior, 29(6), 2501-2511. Retrieved from http://www.ncbi.nlm.nih.gov/pubmed/25722534 
[31] Rung, A., Wranke, F., \& Mattheos, N. (2014). Investigating the use of smartphones for learning purposes by Australian dental students. JMIR Mhealth Uhealth, 2(2), e20.

[32] Sanders, J. (2012). Technology and the delivery of the curriculum of the future: opportunities and challenges. Medical Teacher, 34(7), 534-538.

[33] Sanders, C. E., Field, T. M., Diego, M., \& Kaplan, M. (2002). The relationship of Internet use to depression and social isolation among adolescents. Adolescence, 35, 237-242.

[34] Sapacz, M., Rockman, G., Clark, J. (2016). Are we addicted to our cell phones? Computers in Human Behavior, 57, 153-159.

[35] Shakir, M. (2014). Academic Anxiety as a Correlate of Academic Achievement, Journal of Education and Practice, 5(10), 29-36.

[36] Shu, Q., Tu, Q., \& Wang, K. (2011). The Impact of Computer Self-Efficacy and Technology Dependence on Computer-Related Technostress: A Social Cognitive Theory Perspective. International Journal of HumanComputer Interaction, 27(10), 923-939.

[37] Sung, Y. T. \& Chan, K. E. (2016). The effects of integrating mobile devices with teaching and learning on students' learning performance: A meta-analysis and research synthesis. Computers \& Education, 94, 252-275.

[38] Thatcher, J. B. \& Perrewé, P. L. (2002). An Empirical Examination of Individual Traits as Antecedents to Computer Anxiety and Computer Self-Efficacy. MIS Quarterly, (26)4, 381-396.

[39] Terry, C. A., Mishra, P., Roseth, C. J. (2016). Preference for multitasking, technological dependency, student metacognition, \& pervasive technology use: An experimental intervention. Computers in Human Behavior, 65, 241-251,

[40] Wood, E. \& Zivcakova, L. (2015). Understanding multimedia multitasking in educational settings", pp. 404-453. In L. D. Rosen, N. A. Cheever, \& L. Mark Carrier (Eds.), Wiley handbook of psychology, technology, and society. Wiley-Blackwell. 